\title{
Reinsurance in the Supplementary Health: A Counterfactual Study on the Impacts of Reinsurance Treaties Adoption by Healthcare Plans Operators in Brazil
}

\author{
Caio Alexandrino Costa Areias ${ }^{1}$ \\ caio.areias@alumni.usp.br | (D)0000-0003-3463-1516 \\ João Vinícius de França Carvalho ${ }^{1}$ \\ jvfcarvalho@usp.br | (D)0000-0002-1076-662X
}

\begin{abstract}
The sustainability of the Brazilian Supplementary Health System has been frequently debated, since the number of operators has decreased considerably in recent years after bankruptcy records. In this context, risk transfer mechanisms are presented as options for financial loss mitigation and asset protection. Reinsurance is one of them, but, due to legal understandings, its adoption has been restricted to insurance companies since 2009 and forbidden for other types of operators, such as cooperatives, self-management, and philanthropic enterprises. Using industry microdata and applying the collective risk theory, implemented by the classic ruin model (CramérLundberg), this study aimed to counterfactually verify how reinsurance would impact operators solvency in a hypothetical long-term scenario in which all of them had access to these tools. By introducing quota share, with retentions of $60 \%$ and $80 \%$ of the aggregate expenses, and Stop-Loss treaties, with retention limits of $80 \%$ and $95 \%$, it was verified that the ruin probability decreased in the first case by around $40 \%$ and $20 \%$. However, the adoption of Stop-Loss for aggregate expenses increased the need for solvency capital, as a result of its higher premiums, becoming viable when directed to higher cost events.
\end{abstract}

\section{KEYWORDS}

Supplementary health, reinsurance, risk management, ruin theory

${ }^{1}$ Universidade de São Paulo, São Paulo, SP, Brasil

Received: $11 / 25 / 2019$.

Revised: 04/03/2020.

Accepted: 05/25/2020.

Published Online: 03/01/2021.

DOI: http://dx.doi.org/10.15728/bbr.2021.18.2.6 


\section{INTRODUCTION}

Health issues in Brazil are among the topics most addressed by the media and specialized agencies. This relevance derives from several factors, such as the quality of the services offered, and individual expenses with the supplementary healthcare plans. Simultaneously, demographic questions, such as the aging of the population, wave to a greater demand for healthcare and other evidence point to the overuse of hospital and outpatient services when there is an insurance contract (Maia, Andrade, \& Oliveira, 2004; Layton, Ellis, McGuire, \& van Kleef, 2017). The advance of these numbers concerns both health operators and regulators, generating discussions about possible structural reforms to the current system. For operators, it is a warning sign. With the growing mismatch between revenues and expenses, the probability of bankruptcy increases in the short term. Figure 1 shows the total number of operators and those that had their activities canceled in the last ten years.

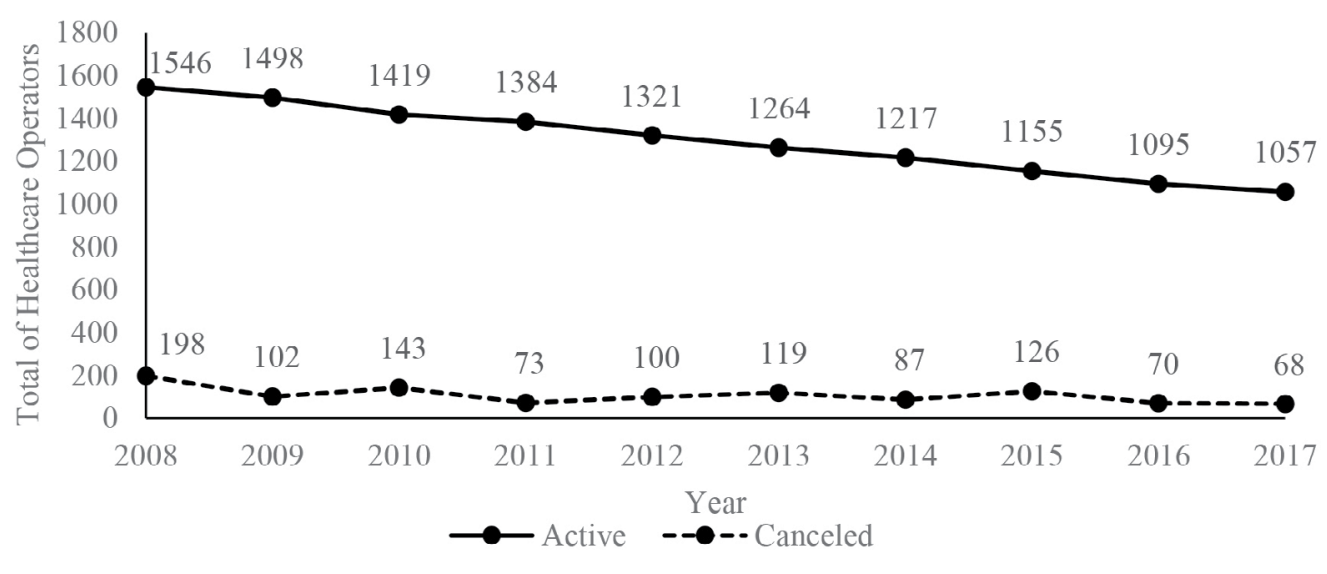

Figure 1. Active Operators and Operators that filed for bankruptcy between 2008 and 2017.

Source: own elaboration, based on data from ANS - Open Data - 2018.

For the healthcare plans beneficiaries, one of the negative consequences of insufficient premium revenues is the need for greater adjustments in the plans' premiums at the moment of contracting or during the term of the contract. Premium readjustments, commonly above economic inflation, are based on the portfolio's historical utilization, either on the frequency (services utilization) or on the severity (financial amounts associated with health events) dimensions. In extreme cases, such as an operator's ruin, beneficiaries are doubly impacted because, in addition to losing direct access to the healthcare network, they should migrate to a new healthcare plan or use the services of the Unified Health System (Sistema Único de Saúde - SUS), whose waiting line tends to be longer due to the unrestricted access of public health services for the whole population.

Given this set of adverse consequences for the entire system, a managerial alternative for health operators is to purchase reinsurance treaties. Reinsurance is a contractual arrangement commonly used by insurance companies to transfer the financial burden of materializing events whose severity exceeds their operational capacity to another company, known as reinsurer, mitigating the unwanted ruin situation. Nevertheless, in Brazil, Complementary Law No. 126/07 restricts operators' access to this type of contract. However, an interesting question to ask is: what if this access would be allowed? Moreover, would there be a relevant impact on the ruin probability of the operators? If so, how big would it be? What treaty design could be the most effective? 
With the goal of answering these questions, this exploratory work aims to simulate the adoption of reinsurance treaties by healthcare plan operators, in order to evaluate its expected effects on the capacity of these companies to remain financially viable, and to propose new arrangements that would guarantee the financial sustainability of this sector. For this, a counterfactual scenario will be considered in which all companies could access reinsurance treaties, despite the specific existing limitation to insurance companies, as verified in Complementary Law No. 126/07.

Besides this introduction, this work is divided into four more sections. The next one, section 2, reviews the legal framework, the empirical literature on reinsurance, the supplementary health, and models of ruin. Section 3 describes the database and methodological procedures. Then, the empirical results are presented in section 4 and, finally, section 5 brings the final considerations.

\section{THEORETICAL AND EMPIRICAL MOTIVATIONS}

\subsection{Supplementary Healthcare Market Overview}

In 2018, Law No. 9,656/98, which regulates the commercialization of healthcare plans, completed 20 years. In this period, the sector experienced strong growth, reaching the adhesion of approximately $25 \%$ of the population (about 47 million users) for healthcare plans with or without dental care and 11\% for exclusively dental plans (about 23 million). According to recent data from the National Health Agency (Agência Nacional de Saúde Suplementar - ANS), as of December 2017, corporate collective healthcare plans had approximately 32 million beneficiaries (67\% of users), individual or family members, 9 million (19\%), and the collective by adhesion, 6 million (14\%). Dental plans had approximately 23 million beneficiaries, divided into about 17 million users for corporate collectives (74\%), 4 million for individual or family members (18\% of users) and 2 million for collective by adhesion (8\%). Compared to December 2016, healthcare plans decreased by $0.6 \%$, while dental plans showed an increase of $6 \%{ }^{1}$.

In addition to Law No. 9,656/98, health operators must follow Normative Resolutions (Resoluçóes Normativas - RN) issued by ANS, such as RN 209/09, which deals with the constitution of Technical Provisions and the maintenance of minimum regulatory capital, $\mathrm{RN}$ $400 / 16$, which sets the parameters and procedures for economic and financial monitoring of the operators, and RN 430/17, which deals with risk management sharing operations between operators $^{2}$. In order to reduce operators' expenses and to decrease both overuse and misuse of healthcare plans, ANS promulgated RN 433/2018, which was intended to regulate the collection of deductibles and co-payments ${ }^{3}$. Despite the short time it remained in force, industry entities were in favor of the measure; but they suggested meanwhile other control and sharing mechanisms, such as reinsurance, to turn the supplementary healthcare market into a sustainable one and to resume growth ${ }^{4}$.

\subsection{The REINSURANCE MARKET AND REINSURANCE IN THE SUPPLEMENTARY HEALTH}

The Brazilian reinsurance market had its state monopoly broken after the enactment of the Complementary Law No. 126/07, which named IRB (Brazilian Reinsurance Institute) as a publiclyheld company under the supervision of the Private Insurance Superintendency (Superintendência de Seguros Privados - SUSEP). Since then, according to official data from SUSEP, the reinsurance ceded premium (gross commission amount) increased from BRL 4 billion in December 2008 to BRL 11 billion in December 2017, an increase of 175\% in nominal terms. Comparing the 
change in premium volume between December 2016 and December 2017, there was an increase of approximately $9 \%$, which was $2.95 \%$ above inflation.

Regarding the reinsurance purchasing by supplementary health operators, Law No. 9,656/98, based on the Provisional Measure No. 2,177-44/01, states that ${ }^{5}$ :

Art.35-M. The operators of the products referred to in item I and paragraph 1 of art. 1 of this Law may enter into reinsurance contracts with companies duly authorized to operate in such activity, as established by Law No. 9,932, as of December 20, 1999, and subsequent regulations.

According to the Health Plans Act, the purchasing of reinsurance treaties by operators is permitted. By the period of its promulgation, treaties were issued by IRB, however, this situation has changed with the advent of the Complementary Law No. 126/07, in which SUSEP became responsible for regulating and overseeing the insurance market. Furthermore, the Complementary Law No. 126/07 introduced new text on reinsurance ${ }^{6}$ :

Art. $2^{\circ}$. The regulation of co-insurance, reinsurance, retrocession and its intermediation shall be exercised by the insurance regulator, as defined by law, subject to the provisions of this Complementary Law.

Paragraph 1. For the purposes of this Complementary Law, it is considered:

I - cedent: the insurance company that contracts reinsurance operation or the reinsurer that contracts retrocession operation; (...)

There is a conflict between the text of the Law No. 9,656/98 and that of the Complementary Law No. 126/07, as the former states that reinsurance can be purchased by all healthcare providers, while the latter restricts it to insurers. This divergence was clarified in 2009, based on the Federal Attorney's Opinion ${ }^{7}$, which delimited the commercialization only to operators established as specialized health insurance companies ${ }^{8}$. Since then, companies such as cooperatives, self-management, and philanthropics enterprises have lost access to reinsurance treaties, while reinsurers have reduced the premium revenues ceded by this sector.

Internationally, in 2010, former US President Barack Obama enacted the Affordable Care Act ("ACA") , also known as "Obamacare", which made it mandatory for all US citizens to join a health insurance plan. The implementation of ACA took place in 2014 and featured, for three years, what was known as "The Three R's": Risk Corridor, Reinsurance and Risk Adjustment, programs that aimed to ensure the health system operation. The main objective of the Reinsurance program was to restrain the individual premium increases, the variation of which would occur due to the total underwriting and loss ratio of high-risk policyholders. Another significant aspect of the program was that it softened expenses for insurers when insured suffered high severity events. In other countries, the use of risk transfer mechanisms, such as reinsurance, varies according to the access to health providers and its regulatory level. When the funding is mainly paid by the government, as in England and Canada, the funding comes from the collection of contributions or funds used to support the health system. In countries with tighter regulations, such as Singapore and France, the health reinsurance market has been developed especially to contain the value of premiums based on utilization and technological advances. 


\subsection{The aCtUarial PERSPECTIVE IN SUPPLEMENTARY HEALTH}

Reinsurance purchasing is a common practice by insurers that allows, through the premium

payment, the assignment of part of its risks in order to guarantee equity stability, reducing undesirable cash flow fluctuations. Garven \& Lamm-Tennant (2003) showed that the strongest motivations for purchasing reinsurance treaties are financial fluctuations, the correlation between investments and indemnities, and the size of the tail distribution of the claims. Cummins et al. (2008) agreed that the reinsurance purchasing reflects in the capital structure and, when it comes to benefits and costs, they mention that the purchase of reinsurance by an insurer reduces the risk of insolvency by stabilizing the loss experience, increasing its capacity, and limiting obligations, in terms of certain risks. However, the amounts paid in this transaction may exceed the actuarial price of the transferred risk; that is, by purchasing a reinsurance treaty, insurers agree to increase their operating expenses in order to reduce underwriting risk. Chen et al. (2001) warn that, despite the market gains, a possible negative effect on the assignment of the risks is that the insurer retains a smaller portion of premiums which, over the long term, or in high claims cycles, may lead to insolvency. The authors also warn that less solvent insurers tend to purchase more reinsurance due to their inability to seek capital in the financial market.

The reinsurance purpose, from the perspective of risk theory, is to reduce the volatility of the aggregate claims. Bowers et al. (1997) define that ruin theory provides the best perspectives on adverse deviations from claims over the long term ${ }^{10}$. Lemos $(2008$, p. 29) states that the "ruin situation arises when the amount of capital that the institution has in its reserves is unable to pay policyholders for losses (claims) resulting from a random event", that "the reinsurance aims to reduce the risks assumed by direct insurers", and also that "the risk reducing decreases an insurer's ruin probability". In a computer simulation of the ruin theory, Kasumo, Kasozi \& Kuznetsov (2018) explored the application of proportional and non-proportional reinsurance in an insurance company whose reserves dynamics followed a diffusion-disturbed risk model. This model differs from the classic Cramér-Lundberg model by adding a variable that measures the financial surplus volatility. They argued that both types of reinsurance decrease the ruin probability, considering both light and heavy tail events, increasing company's solvency, in accordance with Bowers et al. (1997) and Cummins et al. (2008), but, unlike what is seen in the literature, the best strategy was to use the proportional reinsurance.

Wammes et al. (2017), describing the characteristics and patterns of the usage of health insurance in The Netherlands in 2013, report that a quarter of total expenses came from a small share of beneficiaries $-1 \%$ to $5 \%$ of the 4.5 million insured people. For these participants, $75 \%$ of expenses resulted from hospital expenses, $9 \%$ of them with ICU admission and $9 \%$ with more expensive medications. From the $1 \%$ of the mass with the highest levels of utilization, $54 \%$ were made up of people aged 65 and younger, with average spending decreasing along with advancing age. This data suggests that the most expensive treatments are correlated with the share of the highest-spending beneficiaries, that the focus on the elderly can leave many of these participants untreated, and that tailor-made interventions are necessary for sector sustainability. Wammes et al. (2018) report that in the US the problem also lies in the high concentration of expenses in a few beneficiaries: the top-10\%, top- $5 \%$ and top- $1 \%$ high-cost beneficiaries represent respectively $68 \%, 55 \%$ and $24 \%$ of the total expenses. Layton, McGuire \& Sinaiko (2016) describe the operation of Risk Corridor and Reinsurance, the temporary programs under the ACA. Risk Corridor (described as "aggregate Stop-Loss reinsurance") was intended to limit insurers' expenses arising from aggregate losses. Reinsurance was intended to mitigate costs from high-cost individual events. Both programs aimed to reduce insurers' expected expenses and, as 
a result, to set premiums at an affordable final price. Besides, they would also reduce possible underwriting fluctuations from other factors concerning the beneficiaries' acceptance, such as adverse selection, regardless of their clinical history. The authors concluded that both programs achieved consistent levels of underwriting risk reduction and that health insurance policies in effect during the three years of observation behaved similarly to a common reinsurance treaty.

Also in the US, Geruso \& McGuire (2016) collected data from health insurance claims between 2008 and 2009 and simulated empirically the values of fit, power, and balance, which are efficiency metrics, in order to analyze the payment system of health plans when the three ACA programs started. With these results, the authors stated that the Risk Adjustment is not a good pattern for health insurance pricing. They concluded that reinsurance returns a higher power, by acting directly on high severity events. They also suggested that the temporary use of reinsurance be reconsidered and that, in order to maintain the sustainability of the health insurers' payment system and reduce variations in expenses costing, the program be maintained. Schmid \& Beck (2016) implemented a similar study in Switzerland, and concluded that reinsurance strongly reduces incentives for the practice of anti-selection risk. McGuire, Schillo \& van Kleef (2020) extended the study to Germany, The Netherlands and the US, finding similar conclusions.

In the Brazilian context, Maia \& Carvalho (2020) evaluated the possible effects of the introduction of popular plans into the Brazilian health insurance market. Their results, obtained from a realistic database, suggested that if the health plans offered have more attractive relative prices than those prevailing in the market, the anti-selection spiral of the insured portfolio would be so intense that it would make the operation unfeasible for all profiles of health plan operators in all age groups without exception. Alves \& Guimarães (2009) proposed a logistic regression model with 17 financial indicators, simulating the ruin probability of 597 operators during 2005. They found 570 solvent to 27 insolvent operators (ruin probability of $4.52 \%$ ) and inferred that there are three most relevant indicators: Leverage, Profitability, and Activity. In a similar study, Barros (2013) tested the effectiveness of six predictive ruin models with a database built with operators' data from 2009 to 2012, not recommending the model proposed by Alves \& Guimarães (2009) due to its low accuracy and performance.

Sá, Maciel Júnior \& Reinaldo (2017), by applying the Monte Carlo Method and the CramérLundberg model, estimated the ruin probability of a Brazilian healthcare plan operator with 48,000 beneficiaries over a 10 -year period. They noted that, with a $10 \%$ annual premium increase, the ruin probability in the first year is low, but it reverses to $99.28 \%$ in the tenth year. Improving a $13 \%$ annual premium increase, the ruin probability decreases to $49.68 \%$. Both Alves \& Guimarães (2009), Barros (2013) and Sá, Maciel Júnior \& Reinaldo (2017) developed associative models in order to identify which indicators would increase the ruin probability of Brazilian healthcare plan operators. Nevertheless, using the whole health industry's data, and with a more similar approach to Kasumo, Kasozi \& Kuznetsov (2018), this paper aims to verify how reinsurance treaties can alleviate the need for capital in the supplementary health system and in which proportion they would reduce the probability of a company being ruined.

Chan \& Joaquin (2010), in a methodology similar to that applied in this work, identified how Monte Carlo simulations can be used to assist in the purchasing of reinsurance treaties by modeling claims frequency and individual loss severity, assuming that the claims distribution in recent years is a good approximation of the claims distribution in the period taken into account. Considering the three modifications to the contractual structure (no reinsurance; only quota share; hybrid between quota share and excess of loss), the authors concluded that the probability of losing $5 \%$ of the initial capital is decreased from $29.8 \%$ to $0.5 \%$ when applying a hybrid 
reinsurance strategy with quota share and excess of loss. In comparison to this approach, the present work stands out on two points: it is a counterfactual experiment in which it is intended to evaluate the impacts on health operators assuming the unrestricted purchasing of reinsurance treaties; the claims distribution, as explained in the next section, will be fitted to real individual experiences. The next section will present the methodological approach of the ruin model to be applied to the official database of the Brazilian supplementary health sector.

\section{METHODOLOGY AND DATABASE DESCRIPTION}

\subsection{The MATHEMATICAL STRUCTURE AND THE INCORPORATION OF THE REINSURANCE TREATY}

Since the objective of this paper is to estimate the potential effects of purchasing reinsurance treaties on the financial sustainability of health plan operators, this study has an exploratory content. Based on this, it was decided that the analysis would be performed through simulations. To measure the expected effects of these simulations, it is necessary to define the metric from which the sensitivity analysis of the counterfactual scenarios will be made in opposition to the current scenario. This metric will be the ruin probability. In order to estimate the ruin probability for healthcare operators in scenarios with and without reinsurance treaties and compare the results, it is important at first to define the stochastic cash flow process that will allow to evaluate the insolvency. Therefore, the Cramér-Lundberg model will be used (Bowers et al., 1997), according to Equation 1.

$$
U_{t}=U_{t-1}+P_{t}-S_{t}
$$

in which, for all $\mathrm{t} \geq 1$,

$U_{t}$ : Operator's Surplus (Solvency Capital) at time t;

$P_{t}$ : Premiums collected through time t;

$S_{t}=\sum_{i=1}^{N_{t}} X_{i}$

: aggregate claims paid through time $\mathrm{t}$, as a result of the stochastic convolution of random variables $\mathrm{N}_{\mathrm{t}}$ (frequency) and $\mathrm{X}_{\mathrm{i}}$ (severity). All quantities will be assumed to be stationary in time and mutually independent.

Given the initial surplus $U_{0}$ (the only insurer's discretionary amount), the ruin occurs when the surplus $U_{t}$ becomes negative at a certain finite $t$, and the ruin probability $\psi\left(U_{0}\right)$ can be estimated by the Equation 2, as follows.

$$
\psi\left(U_{0}\right)=\mathrm{P}\left(U_{t}<0 \mid \mathrm{U}_{0}\right)
$$

To reproduce this risk process, the database (described in subsection 3.2) will serve as a reference to estimate the initial parameters of Equation 1. The insolvency evaluation of the healthcare operator will be made within a maximum period of 120 months, at any time $t$, from different choices of $\mathrm{U}_{0}$, with the purpose to test the sensitivity of the model. Monthly premium amounts will consist of the collection of pure premiums from the operators' health plans based on sector information and ANS publications about the number of beneficiaries and the evolution of the average commercial prices for the products during period in consideration. As for the random variable $S_{t}$, initial amounts will be established by hospital and outpatient expenses in accordance with the empirical results presented in Tables 1 and 2. 
BBR

18

224

The main challenge will be to define the probability distribution for the expenditure curve at each moment in time, and that will be done from adjustments in the expense distribution initially observed. For the remaining time moments, via the Monte Carlo Method (MCM), the amounts of $S_{t}$ will be simulated over a large number of times from the fitted expenditure curve and the number of occurrences previously observed. By estimating non-parametrically the number of times of insolvency in relation to the total number of simulations, the ruin probability will be appraised.

After that, for the counterfactual scenarios, the random variable $S_{t}$ will be modified to represent the two treaties. According to Deelstra \& Plantin (2014), reinsurance treaties can be systematically classified according to their main characteristics: proportional ${ }^{11}$ or non-proportional ${ }^{12}$. Let $S$ be the severity associated with the aggregate expenses. Thus, a reinsurance contract $h$ can be defined as a transformation in the original random variable as follows:

$$
\left\{\begin{array}{l}
\text { 1) } h(S)=\alpha S, 0 \leq \alpha \leq 1 \text { (proportional); } \\
\text { 2) } h_{d}(S)=\left[\left(S^{\wedge} L\right)\right]=\min \{S ; L\}(\text { non }- \text { proportional }) .
\end{array}\right.
$$

In the proportional case, $\alpha$ represents the retention rate applied to the claims amount that can be obtained by dividing the retained premium by the total premium. The main advantages of this treaty include the ease of implementation and the reduction of moral hazard, since the reinsurer follows the insurer's fortunes. The non-proportional case, in its turn, does not meet the same rate of premiums and claims ceded, leaving one party with a larger portion of the insured risk (in most cases, the reinsurer). The reinsurer is only called for payment if the amount of the claim exceeds the retention limit $(L)$ set by the insurer.

Thus, three distinct scenarios will be evaluated: (i) without any reinsurance structure, (ii) with proportional reinsurance (quota share), and (iii) with non-proportional reinsurance (Stop-Loss). The objective is to demonstrate how much and in what way the purchasing of reinsurance treaties impacts the insolvency situation of a typical supplementary healthcare provider, making it more or less able to respect its obligations to the beneficiaries, and how much the total ceded premium may favor the reinsurer. Broadly speaking, this model aims to test the use of reinsurance in all modalities of supplementary health system operators, despite the market restriction imposed by SUSEP in 2009.

\subsection{Database and Descriptive Analysis}

The database used in this study was built from the information contained in the open data area provided by the ANS website ${ }^{13}$. The information was collected from the spreadsheets presented in the subsections "Hospital Procedures by State" and "Outpatient Procedures by State", which list the expenses reported by service providers to healthcare plan operators and, consequently, to ANS, occurring between July 2015 and December 2016 in two service environments for each of the 26 Brazilian States and the Federal District. Each spreadsheet had 15 columns with variables such as event identification, beneficiary gender, date of occurrence, ICD (International Classification of Diseases) code, and procedure value.

It was first established a data panel containing the values by State over the months. However, due to restrictions of statistical software programs it was used the analysis of monthly cross-sections, with groups of information from both hospital and outpatient procedures, and also by State. 
Some original variables were disregarded, such as event identification, city of occurrence, and ICD sublevels, but a dummy variable was included to distinguish the two types of procedures. As for the data cleansing, the records without indication of gender, and age and values of procedures less than $1.00 \mathrm{BRL}$ were also disregarded. The final database, composed of 18 cross-sections, totaled 467,260,599 observations. In relation to the 510,408,827 initial occurrences, there was a reduction of $8.45 \%$. Table 1 shows the descriptive statistics of procedures with total observation amounts, mean, median and standard deviations.

Table 1

Database Descriptive Statistics - Observations and General Expenses

\begin{tabular}{lccccc}
\hline \multicolumn{5}{c}{ Hospital and Outpatient Procedures } \\
\hline Month/Year & Observations & Total Amount (BRL) & Mean (BRL) & Median (BRL) & S. D. (BRL) \\
\hline July/2015 & $25,097,442$ & $1,857,400,000$ & 74.03 & 55.80 & 263.43 \\
August/2015 & $25,756,626$ & $1,878,800,000$ & 72.92 & 55.00 & 189.19 \\
September/2015 & $25,464,114$ & $1,888,100,000$ & 74.14 & 55.00 & 196.53 \\
October/2015 & $26,613,723$ & $2,016,700,000$ & 75.77 & 57.72 & 172.98 \\
November/2015 & $27,195,981$ & $2,159,400,000$ & 79.41 & 60.00 & 209.80 \\
December/2015 & $24,028,905$ & $1,965,500,000$ & 81.80 & 60.00 & 203.04 \\
January/2016 & $27,425,843$ & $2,217,600,000$ & 80.87 & 60.00 & 524.83 \\
February/2016 & $27,983,925$ & $2,284,800,000$ & 81.63 & 60.00 & 191.25 \\
March/2016 & $33,287,969$ & $2,717,600,000$ & 81.63 & 60.00 & 184.22 \\
April/2016 & $29,951,517$ & $2,492,600,000$ & 83.21 & 60.00 & 190.78 \\
May/2016 & $28,208,317$ & $2,390,800,000$ & 84.75 & 60.96 & 195.40 \\
June/2016 & $27,942,415$ & $2,369,000,000$ & 84.80 & 61.16 & 314.29 \\
July/2016 & $26,549,528$ & $2,273,100,000$ & 85.63 & 61.00 & 445.25 \\
August/2016 & $27,481,919$ & $2,334,800,000$ & 84.97 & 62.00 & 191.36 \\
September/2016 & $22,844,298$ & $1,968,400,000$ & 86.16 & 62.00 & 206.02 \\
October/2016 & $22,641,954$ & $2,001,100,000$ & 88.36 & 63.74 & 205.46 \\
November/2016 & $22,674,852$ & $1,967,800,000$ & 86.79 & 62.06 & 189.94 \\
December/2016 & $16,111,271$ & $1,389,900,000$ & 86.27 & 61.16 & 201.52 \\
\hline Total & $\mathbf{4 6 7 , 2 6 0 , 5 9 9}$ & $\mathbf{3 8 , 1 7 3 , 4 0 0 , 0 0 0}$ & & &
\end{tabular}

Source: own elaboration, based on data from ANS - Open Data - 2018.

Table 1 shows that the observations of hospital and outpatient procedures are reasonably close to the average (around 26 million), with the maximum in March 2016 and the minimum in December 2016. As for expenses, this fact may be seen as well, that is, the monthly total amounts remain close to the average (around BRL 2 billion), with the minimum also in December and the maximum in April 2016. It is important to segregate expense information in hospital and outpatient procedures because, although the averages show an almost linear pattern in time, the medians are smaller, indicating asymmetry to the right, with a lower concentration of occurrences, and "long tail" events, corroborated by higher standard deviations caused by large expenses. Table 2 shows the difference between hospital and outpatient procedures in the first semester of 2016. 
Table 2

Database Description - Observations and Expenses per Procedure in BRL

\begin{tabular}{lcccccccc}
\hline & \multicolumn{3}{c}{ Hospital Procedures } & \multicolumn{4}{c}{ Outpatient Procedures } \\
\hline Month/Year & Observations & Mean & Median & S. D. & Observations & Mean & Median & S. D. \\
\hline January/2016 & 740,797 & 401.68 & 168.00 & 876.85 & $26,685,046$ & 71.97 & 58.47 & 508.74 \\
February/2016 & 765,372 & 382.61 & 160.00 & 841.70 & $27,218,553$ & 73.17 & 59.40 & 122.74 \\
March/2016 & 855,475 & 386.44 & 162.27 & 814.52 & $32,432,494$ & 73.59 & 60.00 & 121.73 \\
April/2016 & 858,315 & 394.44 & 175.00 & 817.21 & $29,093,202$ & 74.03 & 60.00 & 121.76 \\
May/2016 & 788,798 & 397.86 & 165.00 & 852.18 & $27,419,519$ & 75.75 & 60.00 & 124.45 \\
June/2016 & 784,143 & 400.47 & 168.77 & 831.67 & $27,158,272$ & 75.68 & 60.00 & 280.54 \\
\hline
\end{tabular}

Source: own elaboration, based on data from ANS - Open Data - 2018.

Table 2 indicates that the pattern for hospital and outpatient expenses maintains itself since the amounts of observations are reasonably close to the average of occurrences. In both procedures, there is asymmetry to the right (medians lower than the means) suggesting "long tail" presence, clearly for the standard deviations of hospital events, resulting from hospitalizations and longterm treatment. There is also inversion of proportions: for hospital procedures, there are fewer observations and higher averages; for outpatient procedures, more observations and smaller averages.

This descriptive analysis was stratified into two more layers: gender and age group. Age groups were separated according to the classification determined by the ANS: from 0 to 18 years old (range 1), from 19 to 23 (range 2), 24 to 28 (range 3), 29 to 33 (range 4), 34 to 38 (range 5), 39 to 43 (range 6), 44 to 48 (range 7 ), 49 to 53 (range 8), 54 to 58 (range 9), and 59 and over (range 10). Similarly, the average expenses by gender and age group, despite the outliers, remained the same over the period, either for outpatient, hospital (even with some expected variations) or both procedures simultaneously.

In the next section, the Equation 1 model will be tested in three scenarios: in the first one, called the "base scenario", without risk transfer mechanisms; in the second and third ones, proportional (quota share) and non-proportional (Stop-Loss) reinsurance treaties, respectively given by Equation 3, will be introduced so that the results for Equation 2 are compared to the base scenario.

\section{MODEL APPLICATION AND RESULTS}

An algorithm ${ }^{14}$ was implemented to receive the database and define premium income and aggregate claims amounts in order to estimate the ruin probability based on the Equation 1. Due to operational limitations, some adjustments were required. The first adaptation was made to the database: to accommodate a satisfactory number of events for the execution of the algorithm, one of the 18 cross-sections was chosen, since there is clear stability in the expenditure behavior of the expenses. Once it has the largest number of observations, the cross-section from March 2016 was chosen. The next step was to establish a sample of this cohort for the application of the model. Using the software $\mathrm{R}$, a random sample containing $17.5 \%$ of the events was extracted $(5,825,395$ observations). The following step was to establish the number of beneficiaries for the expenses sample. For that, we considered the numbers of beneficiaries that were reported on the ANS website in December 2015 (49,212,099) and December 2016 (47,630,794), which, by linear interpolation, resulted in an estimated population of $48,816,773$ beneficiaries. Fitting this 
number to the model and assuming the linear relationship, we took $17.5 \%$ of this population and applied an adjustment factor of 0.9589 for missing information on gender, age, and baseline values, resulting in $8,191,841$ participants.

As for the pure premium values by age group, the amounts were estimated from the 2015 ANS Pricing Panel ${ }^{15}$. Based on the amount of BRL 610.24, which depicts the average commercial premium of health plans in December 2015 in the Federation Units for the 44 to 48 years old (range 7), a relationship between the ranges within ANS specifications and discounting the average total loadings by age group, pure premiums were found by age group, as shown in Table 3 .

Table 3

Beneficiaries, Pure Premiums, and Procedure Expenses by Age Group

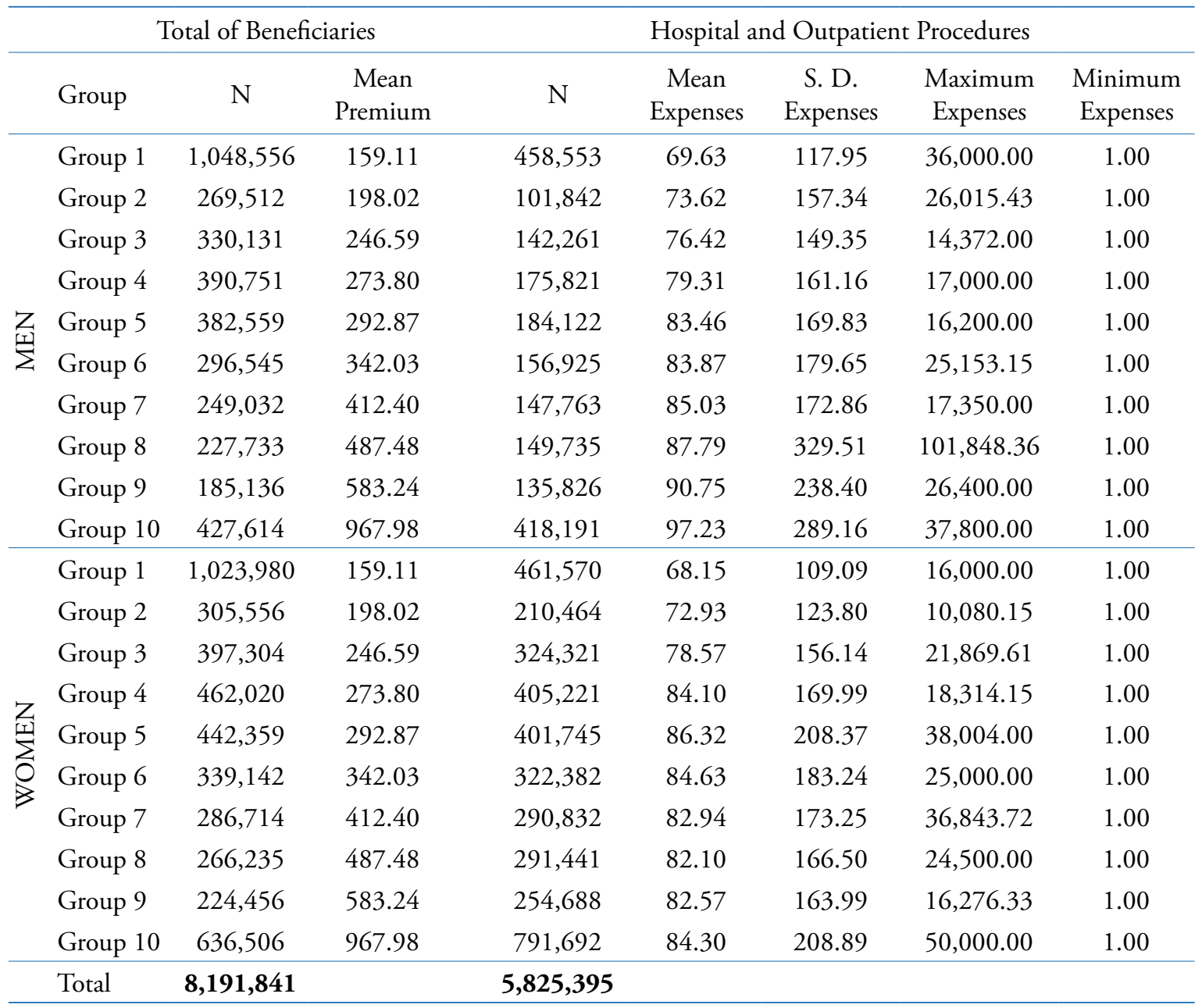

Source: own elaboration.

The last adjustment was made in the expense distribution with hospital and outpatient procedures to be used for stochastic development of simulations over different time periods. From the amounts observed in the database, different probability distributions were fitted to data by maximum likelihood and their parameters were obtained. To fit the curve that best described the expense pattern, seven parametric distributions were taken: Exponential, Gamma, Normal, Log-Normal, Weibull, Inverse Weibull and Pareto, and, out of them, the one with the lowest BIC (Bayesian Information Criterion) index was chosen. 
Table 4

Best fit distributions, by age group and by gender, and their parameters

\begin{tabular}{|c|c|c|c|c|c|c|c|c|c|c|c|c|}
\hline Group & & Distr. & $\mu$ & $\sigma$ & & Distr. & $\mu$ & $\sigma$ & & Distr. & $\mu$ & $\sigma$ \\
\hline 1 & \multirow{10}{*}{ 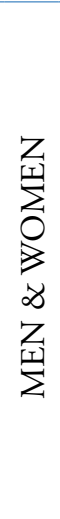 } & Log-normal & 3.86 & 0.88 & \multirow{10}{*}{$\underset{\text { 省 }}{ }$} & Log-normal & 3.87 & 0.89 & \multirow{10}{*}{$\sum_{\substack{Z \\
⿱ 亠 䒑}}$} & Log-normal & 3.85 & 0.88 \\
\hline 2 & & Log-normal & 3.83 & 0.95 & & Log-normal & 3.80 & 0.98 & & Log-normal & 3.84 & 0.94 \\
\hline 3 & & Log-normal & 3.86 & 0.97 & & Log-normal & 3.81 & 1.00 & & Log-normal & 3.88 & 0.96 \\
\hline 4 & & Log-normal & 3.89 & 0.99 & & Log-normal & 3.82 & 1.02 & & Log-normal & 3.92 & 0.98 \\
\hline 5 & & Log-normal & 3.91 & 1.00 & & Log-normal & 3.85 & 1.04 & & Log-normal & 3.94 & 0.98 \\
\hline 6 & & Log-normal & 3.90 & 1.00 & & Log-normal & 3.85 & 1.04 & & Log-normal & 3.92 & 0.98 \\
\hline 7 & & Log-normal & 3.90 & 1.00 & & Log-normal & 3.86 & 1.04 & & Log-normal & 3.91 & 0.98 \\
\hline 8 & & Log-normal & 3.89 & 1.01 & & Log-normal & 3.88 & 1.05 & & Log-normal & 3.90 & 0.99 \\
\hline 9 & & Log-normal & 3.90 & 1.02 & & Log-normal & 3.90 & 1.06 & & Log-normal & 3.90 & 1.00 \\
\hline 10 & & Log-normal & 3.88 & 1.05 & & Log-normal & 3.91 & 1.08 & & Log-normal & 3.87 & 1.03 \\
\hline
\end{tabular}

Source: own elaboration.

For the total sample, by analyzing the results, the distribution with the best fit was the LogNormal, with parameters 3.88 ( $\mu$, the mean) and 0.99 ( $\sigma$, the standard deviation). The same operation was repeated for the 10 age groups of the sample and for sex per group, all of which also resulted in Log-Normal, in line with international evidence (Deb \& Norton, 2018). Thus, the expected assumption of the asymmetric right-tailed and long-tailed statistical curves (extreme events) was verified, as seen in Table 4. Once these adjustments were completed, 1,000 trajectory simulations were performed within the 120-month horizon of Equation 1 via Monte Carlo Method in order to calculate the aggregate expenses by sample, by age group, and by sex, and thus estimating the ruin probability for each of these segmentations. The results, without and with reinsurance treaties, are presented as follows.

\subsection{Results - Base Scenario}

The evaluation of the first scenario consisted of 1,000 simulations of ruin model (Equation 1) over a 120-month period, with an initial capital equal to zero, revenues generated by the product between the pure premium and total number of beneficiaries, both by age group, and claims (aggregate expenses) from the random simulations of expenses by the fitted curves. Unexpectedly, for all cases, no insolvency situation was verified. This may be due to the massification of the outpatient procedures, whose concentration of the expenses is below the average, considering the lower number of occurrences of hospital procedures and the higher proportion of revenue in relation to expenses in the original chosen period, which was the basis for the stochastic simulations.

In order to eliminate the financial impacts from the database or adjustments, the minimum expenses were hardened in four scenarios which are, respectively, equivalent to BRL 100.00, BRL 300.00, BRL 500.00, and BRL 1,000.00, keeping all other elements constant. The probability distributions fitted to expenses were re-estimated taking into account these new minimum values and the maximum likelihood estimation method. There was a change in the distribution for the aggregate claims' estimation from Log-Normal to Inverse Weibull in all cases. Applying the risk model from Equation 1, the occurrence of ruin in the simulated processes has started to appear with the minimum expense amount of BRL 300.00. For this scenario, the total expenses of the sample can be fitted into an Inverse Weibull distribution, with parameters 2.96 ( $\kappa$, the form) and $4.33(\lambda \text {, the scale })^{16}$. Ranging the solvency capital from BRL 0 to 50 billion, at every one billion, 
it has been found that the process leaves the surely insolvent situation between BRL 43 and 44 billion. This was repeated for the age groups and for sex by age group. For the first case, as seen in the solvency capital of Table 5, unexpectedly the lower age group is the last to emerge from a hypothetical insolvency situation, between BRL 19 and 20 billion, indicating lower premiums revenues against expenses. In contrast, no insolvency was found for the higher age range.

Table 5

Ruin Probabilities - Age Group (Both Genders) - Minimum Expense BRL 300.00

\begin{tabular}{ccccccccccc}
\hline \multirow{2}{*}{$\begin{array}{c}\text { Age } \\
\text { Group }\end{array}$} & \multicolumn{10}{c}{ Solvency Capital $\left(\mathrm{U}_{0}\right)$ - in BRL billions } \\
\cline { 2 - 29 } & 11 & 12 & 13 & 14 & 15 & 16 & 17 & 18 & 19 & 20 \\
\hline 1 & $100 \%$ & $100 \%$ & $100 \%$ & $100 \%$ & $100 \%$ & $100 \%$ & $100 \%$ & $65,1 \%$ & $0 \%$ & $0 \%$ \\
2 & $0 \%$ & $0 \%$ & $0 \%$ & $0 \%$ & $0 \%$ & $0 \%$ & $0 \%$ & $0 \%$ & $0 \%$ & $0 \%$ \\
3 & $100 \%$ & $0 \%$ & $0 \%$ & $0 \%$ & $0 \%$ & $0 \%$ & $0 \%$ & $0 \%$ & $0 \%$ & $0 \%$ \\
4 & $100 \%$ & $100 \%$ & $100 \%$ & $0 \%$ & $0 \%$ & $0 \%$ & $0 \%$ & $0 \%$ & $0 \%$ & $0 \%$ \\
5 & 100 & $100 \%$ & $0 \%$ & $0 \%$ & $0 \%$ & $0 \%$ & $0 \%$ & $0 \%$ & $0 \%$ & $0 \%$ \\
6 & $0 \%$ & $0 \%$ & $0 \%$ & $0 \%$ & $0 \%$ & $0 \%$ & $0 \%$ & $0 \%$ & $0 \%$ & $0 \%$ \\
7 & $0 \%$ & $0 \%$ & $0 \%$ & $0 \%$ & $0 \%$ & $0 \%$ & $0 \%$ & $0 \%$ & $0 \%$ & $0 \%$ \\
8 & $0 \%$ & $0 \%$ & $0 \%$ & $0 \%$ & $0 \%$ & $0 \%$ & $0 \%$ & $0 \%$ & $0 \%$ & $0 \%$ \\
9 & $0 \%$ & $0 \%$ & $0 \%$ & $0 \%$ & $0 \%$ & $0 \%$ & $0 \%$ & $0 \%$ & $0 \%$ & $0 \%$ \\
10 & $0 \%$ & $0 \%$ & $0 \%$ & $0 \%$ & $0 \%$ & $0 \%$ & $0 \%$ & $0 \%$ & $0 \%$ & $0 \%$ \\
\hline
\end{tabular}

Source: own elaboration.

Therefore, it can be noted that the insolvency decreased as the solvency capital increased. Once it is a market with revenues in the billions, the visualization of the ruin probability decay tends to be difficult as it occurs in the millions.

\subsection{Results - With Reinsurance Treaties}

Taking the base scenario of the previous subsection, with the minimum expense equivalent to BRL 300.00, the proportional (quota share) and non-proportional (Stop-Loss) reinsurance treaties were tested. For the quota share treaties, the values of $80 \%$ and $60 \%$ were assumed for $\alpha$, from Equation 3, which refers to the proportion of premiums and claims retained by the operators. In the first case, it has been found that the insolvency situation of the sample was left between BRL 34 and 35 billion of solvency capital, compared to the BRL 43 to 44 billion of the base scenario. This is a financial relief of around BRL 10 billion for healthcare providers, a smoothing of $20 \%$ of the solvency capital. In the second case, the result fell to BRL 26 to 27 billion, further reducing the need for solvency capital. These results are aligned with those shown by Garven \& Lamm-Tennant (2003) and Cummins et al. (2008).

If both groups, age and age by gender, are evaluated in the same ruin model, with quota share treaties assuming $\alpha$ as $80 \%$ and $60 \%$, there is also a softening of the solvency capital needed. The three most insolvent curves of age groups were taken in relation to the premiums' revenues: the first age group ( 0 to 18 years old), the first male age group ( 0 to 18 years old) and the fourth female age group ( 29 to 33 years old). In all of them, there was a reduction in ruin probability with the increase of solvency capital and with the decrease of retention of premiums and claims - that is, with a higher percentage ceded to the reinsurer. 
BBR

18

230

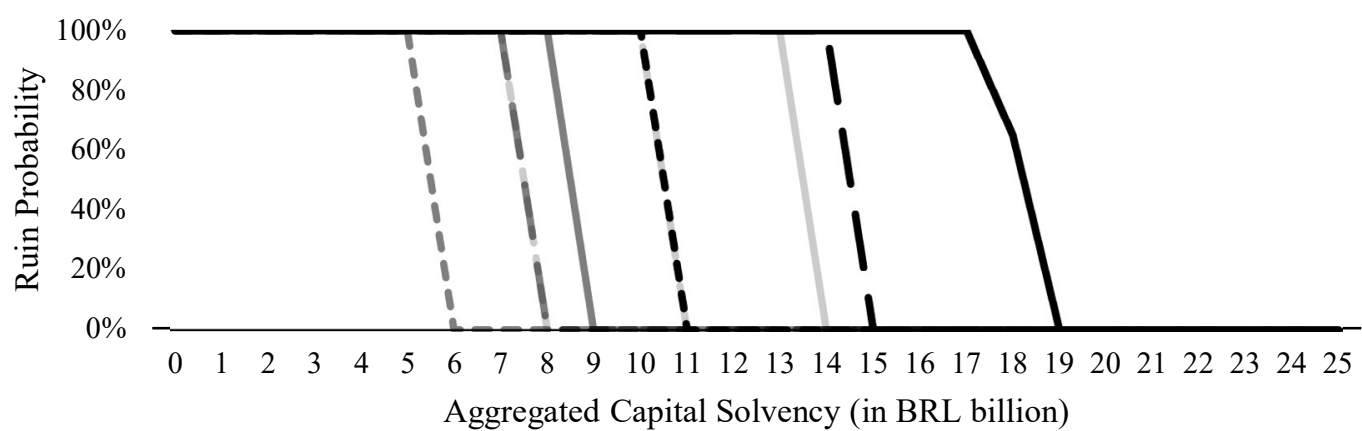

Group $1(\mathrm{M} \& \mathrm{~W})$
Group 1M
Group 4W

Figure 2. Comparison between Solvency Capital and Ruin Probability by Age Group and Sex, with the purchasing of proportional reinsurance treaties (quota share).

Source: own elaboration.

With these results, it is evident that the purchasing of quota share treaties may contribute to the health operators' solvency, especially by reducing the required capital for operation - in this study, a reduction from 20 to $40 \%$ of capital. However, Chen et al. (2001) emphasized that there would be a negative impact on premium revenues.

For the purchasing of Stop-Loss treaties, two scenarios were also conceived: the first one with a retention limit of $80 \%$ of the operators' total expenses per period and the second with a limit of $95 \%$. The reinsurance premium was calculated as the average aggregate expenses ceded, weighted by the probabilities of tail events, i.e., expenses whose values exceed an empirical threshold ( $20 \%$ and $5 \%$, respectively). Subsequently, to the risk process (Equation 1) for each time t, the corresponding reinsurance premium was subtracted from premium revenues, in addition to the aggregate claims retained by the operators.

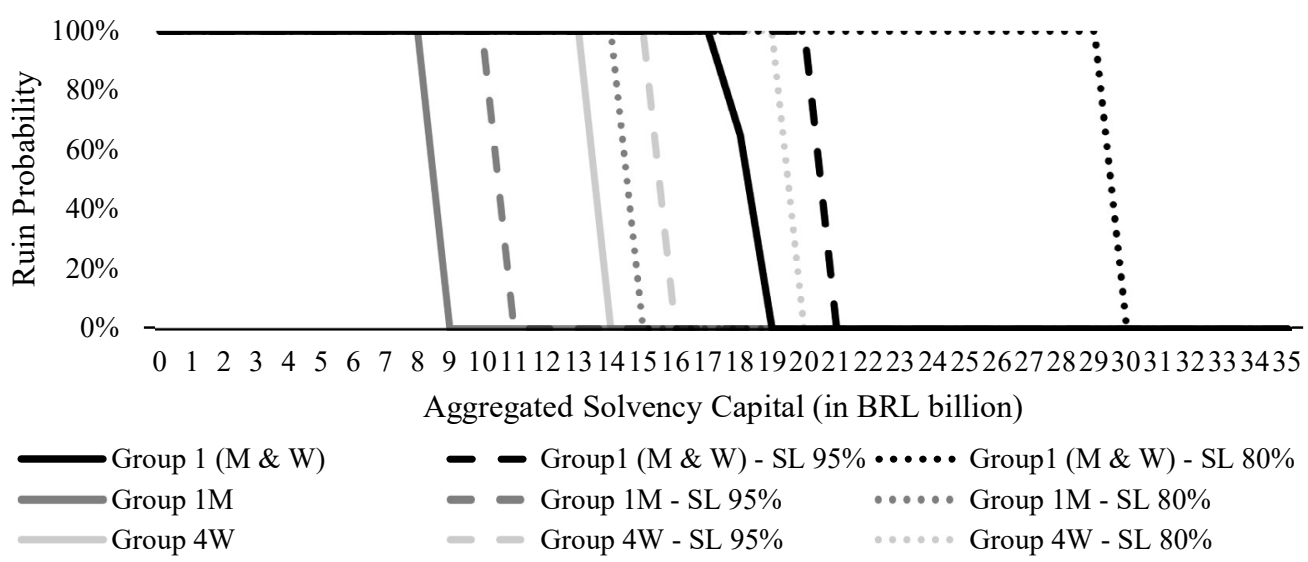

Figure 3. Comparison between Solvency Capital and Ruin Probabilities by Age Group and Sex, with the purchasing of non-proportional reinsurance treaties (Stop-Loss).

Source: own elaboration. 
It was expected that the imposition of a threshold to transfer risks to the reinsurer could mitigate the solvency capital, as the insurer would be yielding the highest possible indemnity amounts. However, it was found that, no matter the retention volume (whether $80 \%$ or $95 \%$ ), the solvency capital needed to maintain the same ruin probability increased from BRL 44 billion to 126 billion (with $80 \%$ retention) and 65 billion (95\%). If age group and sex segmentation are considered, similar behavior is observed: as shown in Figure 3, the separation of BRL 30 and 21 billion for age group 1 in comparison to the BRL 19 billion base scenario, and BRL 20 and 16 billion in comparison to the BRL 14 billion for women in age group 4 . This effect is explained by the fact that Stop-Loss has the highest reinsurance premium among all reinsurance treaties. Since the value of the reinsurance premium transferred is measured as the expected tail (expected shortfall), it does not respect the proportionality defined in the contract, as in the case of quota share.

There is a similar evidence in the literature: Cummins et al. (2008) mention that the reinsurance cost may be higher than the actuarial fair value of the negotiated risk for insurers operating shortterm contracts (such as the health care contracts in Brazil). Thus, the ceded portion in reinsurance premiums may worsen the financial situation by bringing insurers to more potential insolvency scenarios, despite the protection provided against high severity outliers (typical insurable risk). Moreover, the data (Tables 2 and 3) show that operators in Brazil experience a high number of occurrences of outpatient procedures, whose low average values could not justify the purchasing of Stop-Loss treaties, except for recurrent events or those that are more expensive, such as hospital ones (on a smaller scale, with greater severity).

Figure 4 summarizes the scenarios analyzed, with and without reinsurance treaties, showing that the adoption of these mechanisms, despite the legal restriction, can help the financial sustainability of healthcare plan operators.

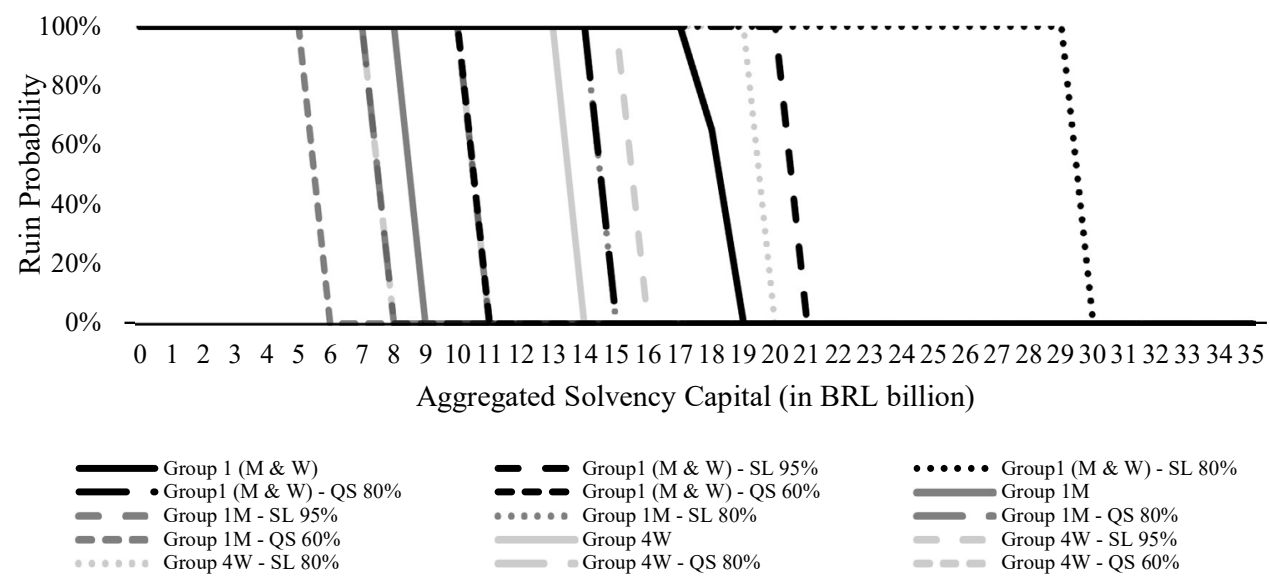

Figure 4. Comparison between Solvency Capital and Ruin Probability by Age Group and Sex, with the purchasing of quota share and Stop-Loss treaties.

Source: own elaboration.

\section{FINAL REMARKS}

The financial sustainability of the supplementary health industry in Brazil has been widely discussed, as its funding has had severe impacts in recent years. Regulatory changes, the aging of the population, and medical and hospital costs variation above inflation are some of the factors that directly affect healthcare plan operators. If their accounts are unbalanced, these changes may interfere their results and they may become insolvent and ultimately ruins can be declared. 
Intrinsic to companies that work with a large number of risks, insolvency is a recurring theme in the actuarial literature and tends to be mitigated in several ways. In both risk management and asset protection, the aim is to minimize the ruin probability of a company. And one of the mechanisms that an insurer can use is the reinsurance, as one or more reinsurers assume, through a formal contract and premium payment, the liability to indemnify the ceding company from the maximum indemnity limit.

Given this context, the present work, based on stochastic risk processes and the ruin theory, used official data from the supplementary health industry, seeking to conduct a counterfactual study comparing the current scenario of health operators to a hypothetical scenario, with the introduction of proportional and non-proportional reinsurance treaties in order to ascertain how and how much the medium and long-term insolvency situation could be solved. The results suggest that purchasing proportional reinsurance (quota share) may improve the solvency of healthcare providers, softening the required capital by 20 to $40 \%$. By purchasing the non-proportional Stop-Loss treaty, the results indicated a higher need for solvency capital to maintain the same level of ruin probability found in other scenarios, due to the high premiums associated with tail events, which may suggest caution in their adoption, even for high severity events such as hospital procedures.

Finally, it is suggested that, if the reinsurance purchasing in supplementary health is allowed, future studies should address not only the treaties indicated here, but also coordinate them with other contract options and other risk transfer tools, like deductibles and co-payments. Based on evidence found in this exploratory study, it is also possible to test hypotheses of effectiveness regarding the adoption of mixed contractual arrangements by supplementary healthcare plan operators of different legal natures, assisting managers of the sector in making decisions. Moreover, new databases could be used, since TISS does not yet cover the entire Brazilian market, which is one of the main limitations of this study.

\section{REFERENCES}

Barros, J. L. (2013). Aplicação de Modelos de Previsão de Insolvência nas Operadoras de Planos de Saúde do Brasil. Dissertação de Mestrado. Fundação Instituto Capixaba de Pesquisas em Contabilidade, Economia e Finanças, Espírito Santo.

Bowers, N. L., Gerber, H. U., Hickman, J. C., Jones, D. A., \& Nesbitt, J. (1997). Actuarial Mathematics. The Society of Actuaries.

Chan, L. S., \& Joaquin, D. C. (2010). Using simulation to support the reinsurance decision of a medical stop-loss provider. Insurance Markets and Companies: Analyses and Actuarial Computations, v. 1 , n. 2, p. $65-77$.

Chen, Y., Hamwi, I., \& Hudson, T. (2001). The effect of ceded reinsurance on solvency of primary insurers. International Advances in Economic Research, v.7(1), p. 65-82.

Cummins, J. D., Dionne, G., Gagné, R., \& Nouira, A. (2008). The Costs and Benefits of Reinsurance. Cahiers de recherche 08-04, HEC Montréal, Institut d'économie appliquée.

Deb, P., \& Norton, E. C. (2018). Modeling Health Care Expenditures and Use. Annual Review of Public Health, 39, 489-505.

Deelstra, G., \& Plantin, G. (2014). Risk Theory and Reinsurance. EAA Series ed. London: Springer.

Garven, J. R., \& Lamm-Tennant, J. (2003). The Demand for Reinsurance: Theory and Empirical Tests. Insurance and Risk Management, v. 7, n. 3, pp. 217-237. 
Geruso, M., \& McGuire, M. (2016). Tradeoffs in the Design of Health Plan Payment Systems: Fit, Power and Balance. American Jornal of Health Economics, v. 47, p. 1-19.

Guimarães, A. L. S., \& Alves, W. O. (2009). Prevendo a Insolvência de Operadoras de Planos de Saúde. Revista de Administração de Empresas, v. 49, n. 4, p. 459-471.

Kasumo, C., Kasozi, J., \& Kuznetsov, D. (2018). On Minimizing the Ultimate Ruin Probability of an Insurer by Reinsurance. Journal of Applied Mathematics, v. 2018, p. 1-11.

Layton, T. J., Ellis, R. P., McGuire, T. G, \& Van Kleef, R. (2017). Measuring efficiency of health plan payment systems in managed competition health insurance markets. Journal of Health Economics, 56, 237-255.

Layton, T. J., McGuire, T. G., \& Sinaiko, A. (2016). Risk Corridors and Reinsurance in Heatlh Insurance Marketplaces. American Journal of Health Economics, v. 2, n. 1, pp. 66-95.

Lemos, S. R. R. (2008). Probabilidade de Ruina no Mercado de Seguros: Fundamentos Teóricos e Alguns Resultados de Simulação. Dissertação de Mestrado. Universidade Federal de Pernambuco, Pernambuco.

Maia, A. C., Andrade, M. V., \& Oliveira, A. M. H. C. (2004). O risco moral no sistema de saúde suplementar brasileiro. Anais do XXXII Encontro Nacional de Economia.

Maia, A. C., \& Carvalho, J. V. F. (2020). A espiral de antisseleção no mercado brasileiro de planos de saúde individuais. Estudos Econômicos, v. 50, n. 3, pp. 535-568.

McGuire, T. G., Schillo, S., \& van Kleef, R. C. (2020). Reinsurance, Repayments, and Risk Adjustment in Individual Health Insurance: Germany, the Netherlands, and the US Marketplaces. American Journal of Health Economics, 6(1), 139-168.

Sá, M. C., Maciel Jr., J. N., \& Reinaldo, L. M. (2017). Processo de Ruína Finito: Um Estudo de Caso na Saúde Suplementar no Brasil. Revista Evidenciação Contábil \& Finanças, v. 5, n. 2, p. 88-103.

Schmid, C. P. R., \& Beck, K. (2016). Re-insurance in the Swiss health insurance market: Fit, power, and balance. Health Policy, 120(7), 848-855.

Wammes, J. J. G., Tanke, M., Jonkers, W., Westert, G. P., Van Der Wees, P. J., \& Jeurissen, P. P. T. (2017). Characteristics and healthcare utilisation patterns of high-cost beneficiaries in the Netherlands: a cross-sectional claims database study. BMJ Open; v7: e017775.

Wammes, J. J. G., Tanke, M., Westert, G. P., Van Der Wees, P. J., \& Jeurissen, P. P. T. (2018). Systematic review of high-cost patients' characteristics and healthcare utilisation. BMJ Open, 8:e023113. 


\section{APPENDIX}

The purpose of this Appendix is to briefly and succinctly present the algorithm used to estimate the ruin probabilities.

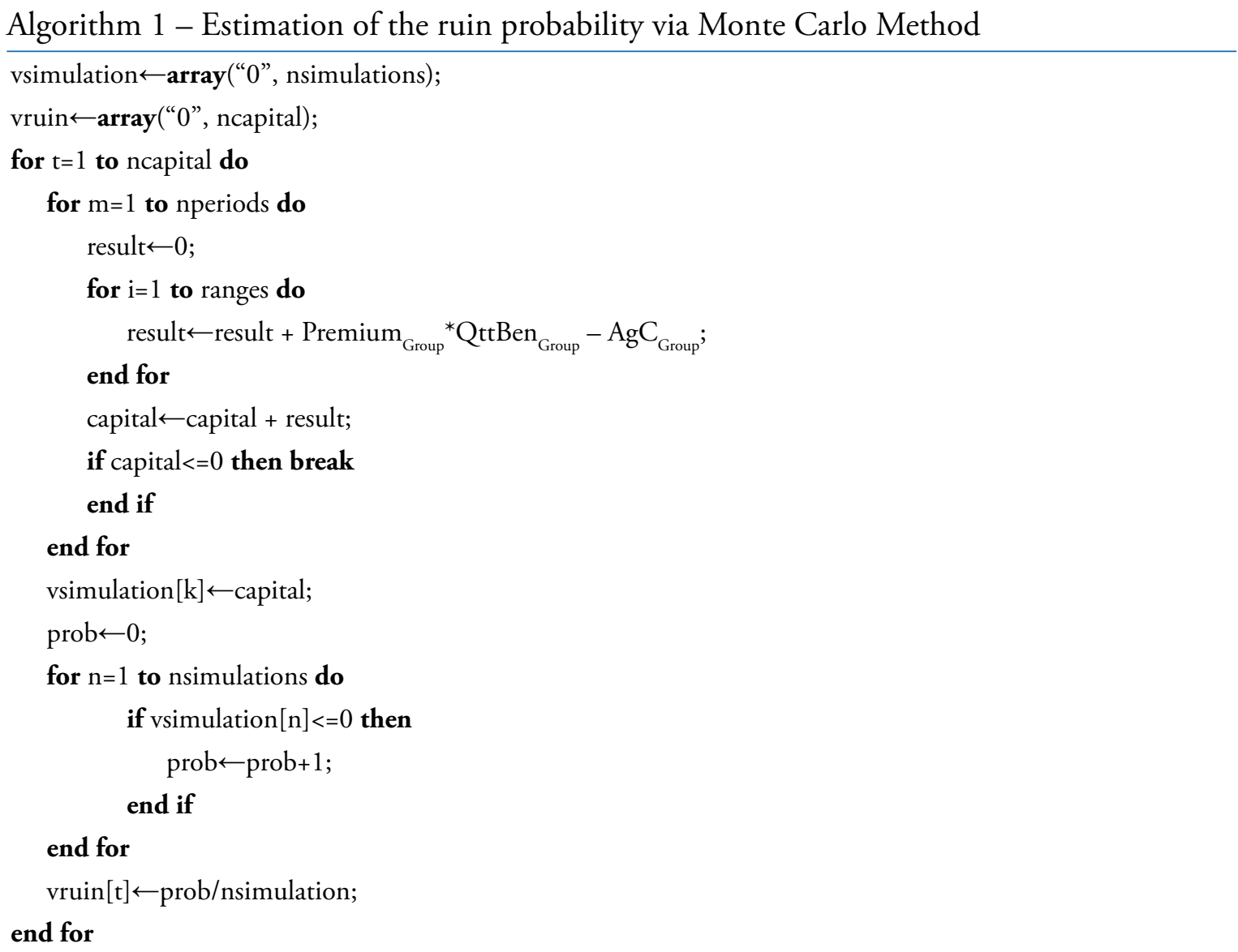


1 AGÊNCIA NACIONAL DE SAÚDE SUPLEMENTAR - ANS. Rio de Janeiro, 2018. Industry Data. General Data. Available at <http://www.ans.gov.br/perfil-do-setor/dados-gerais > Accessed in: June 28, 2018.

2 Idem. ANS Normative Resolutions can be accessed through the legislation search system at <http://www.ans.gov.br/legislacao/busca-de-legislacao>. Acessed in: May 27, 2018.

3 AGENCIA NACIONAL DE SAÚDE SUPLEMENTAR - ANS. News: Co-participations and Deductibles. Rio de Janeiro, June 28, 2018. Available at <http://www.ans.gov.br/aans/noticias-ans/ consumidor/4499-ans-define-regras-para-cobranca-de-coparticipacao-e-franquia-em-planos-desaude>. Accessed in: June 28, 2018.

4 CONFEDERAÇÃO NACIONAL DAS SEGURADORAS (CNSEG). Rio de Janeiro, April 12, 2018. News: Reinsurance Meeting Discusses Risk Sharing in Supplementary Health. Available at <https://cnseg.org.br/noticias/encontro-de-resseguro-discute-compartilhamento-de-riscos-nasaude-suplementar.html>. Acesso em: 27 jan. 2021.

5 Available at <http://www.planalto.gov.br/ccivil_03/Leis/L9656.htm> Accessed in: November 24, 2018.

6 Availabel at <http://www.planalto.gov.br/ccivil_03/leis/lcp/Lcp126.htm> Accessed in: November $24,2018$.

7 Federal Attorney's Opinion - Susep/Administrative Affairs Coordination 50.104/2008.

8 AGÊNCIA NACIONAL DE SAÚDE SUPLEMENTAR - ANS. Rio de Janeiro, June 23, 2009. News: Reinsurance in the Supplementary Health. Available at <http://www.ans.gov.br/a-ans/salade-noticias-ans/a-ans/1073-resseguro-na-saude-suplementar>. Accessed in: May 27, 2018.

9 Law available at <http://housedocs.house.gov/energycommerce/ppacacon.pdf $>$. Accessed in: June 29, 2018.

10 The theoretical proportional and non-proportional reinsurance instruments and the ruin model employed in this study will be defined mathematically in the methodological subsection 3.1.

11 The most common types of proportional reinsurance treaties are quota share and surplus. More details about them can be found in Deelstra \& Plantin (2014).

12 The most common types of non-proportional reinsurance treaties are excess of loss, aggregate loss and stop-loss. More details about them can be found in Deelstra \& Plantin (2014).

13 Data available at <http://dados.gov.br/organization/agencia-nacional-de-saude-suplementar-ans $>$. Access in: November 10, 2018.

14 For all database treatments and all ruin model simulations, we used the statistical software R, version 3.4.0.

15 This panel contains price and cost information for operators registered with ANS. Available at <https://www.ans.gov.br/images/stories/Materiais_para_pesquisa/Perfil_setor/Foco/painel_ precificacao2015_completo.pdf>. Accessed in: November 10, 2018.

16 For the purposes of this study, only the parameters of the Inverse Weibull curves were informed for age groups and genders by age groups of the scenario in which the minimum expense was BRL 300.00. The parameters for the other scenarios were omitted due to the textual space available. If there is interest in any other value, the authors can be contacted for providing further information. 